\title{
A MULHER E A EXTRAÇÃO CLANDESTINA DE INERTES EM CABO VERDE
}

woman and the illegal extraction of inert materials in Cape Verde

\author{
Ermelinda Lopes* \\ Lúcio Cunha**
}

\section{Resumo}

Com o presente trabalho pretendemos avaliar a importância social das mulheres no processo extrativo clandestino de areias e cascalhos em Cabo Verde e explicar como é que as mulheres podem participar e contribuir para uma extração sustentável e para a consequente redução de impactes do processo extrativo clandestino. Com base na observação direta e participativa no terreno realizaram-se inquéritos e conversas informais com as trabalhadoras que extraem os inertes, fez-se o registo dos impactes ambientais em fotografia e a sua avaliação através das matrizes de interacão de Leopold, em funcão do local da exploração, no caso, as ribeiras de Flamengos e Principal, no concelho de S. Miguel e a de Cuba, no concelho de Tarrafal.

/Palavras-chave: Mulher, Extração Clandestina de Inertes (Areia e Cascalho), Impactes Ambientais, S. Miguel, Tarrafal e Ilha de Santiago, Cabo Verde.

\begin{abstract}
This study aims to assess the social importance of women in the illegal extraction of sand and gravel in Cape Verde and explain how women can participate and contribute to a sustainable extraction and the consequent reduction in illegal extraction process. Based on direct observation on the field, there were realized surveys and informal conversations with the workers who extract the inert material, it was held the record of environmental impacts in photography and the environmental impacts assessment through the interaction matrices of Leopold, depending on the site of operation in the case, in the rivers of Flanders and Principal, in the municipality of S. Miguel, and Cuba, in the municipality of Tarrafal.
\end{abstract}

Key words: Women, Clandestine extraction of sand and gravel, Environmental Impacts, S. Miguel, Tarrafal and Santiago Island, Cape Verde.

\section{Résumé}

Cette étude vise à évaluer l'importance sociale des femmes dans l'extraction illégale de sable et de gravier dans le Cap-Vert et expliquer comment les femmes puissent participer et contribuer à l'extraction durable et la réduction des impactes des processus d'extraction illégale. Basés sur l'observation directe sur le terrain, nous avons mené des enquêtes réalisées et les conversations informelles avec les travailleurs qui extraient la matière inerte. Les impacts environnementaux ont été enregistrés dans la photographie et son évaluation à travers les matrices d'interaction de Léopold, en fonction sur le site de fonctionnement dans le cas, dans les rivières de la Flandre et principal, dans la municipalité de $\mathrm{S}$. Miguel, et à Cuba, dans la municipalité de Tarrafal.

Mots-clés: Femmes, Extraction clandestine de sable et de gravier; Impacts environnementaux, S. Miguel, Tarrafal et l'île de Santiago, Cap-Vert.

(*) Msc em Geografia Física, Ambiente e Ordenamento do Território pela Universidade de Coimbra - Cx. Postal 3004-530, Coimbra, Portugal, Tel: (+351) 939352662 - ermeslopes77@hotmail.com

(**) Prof. Dr. do Departamento de Geografia da Universidade de Coimbra - Cx. Postal 3004-530, Coimbra, Portugal, Tel: (+351) 939352662 - luciogeo@ci.uc.pt 


\section{INTRODUÇÃO}

As características peculiares de Cabo Verde, nomeadamente, o seu carácter arquipelágico, a forte densidade demográfica $\left(122 \mathrm{hab} . / \mathrm{Km}^{2}\right)$, o rápido crescimento da população $(44 \%$, nos últimos 20 anos), a forte migração recente do campo para as cidades ( $62 \%$ da população a viver em meio urbano), uma elevada taxa de desemprego (10,7\%, que afeta mais a população feminina, com 12,1\%), as condições climáticas, especialmente, a irregularidade da precipitação e a falta dos recursos naturais para a construção civil, determinam condições de vida bastante difíceis para a população cabo-verdiana, justificando a forte emigração, principalmente a nível do sexo masculino (LOPES, 2010:16) e, a nível interno, a entrada da mulher no processo extrativo clandestino, com tremendos impactes ambientais e com a própria mudança nas técnicas da construção civil e na arquitetura das habitações.

Quadro 1 - Alguns dados demográficos em Cabo Verde, na Ilha de Santiago, no concelho da Praia e nos concelhos em estudo

\begin{tabular}{|c|c|c|c|c|c|c|}
\hline & POPULAÇÃO & $\begin{array}{c}\text { DENSIDADE } \\
\text { POPULACIONAL } \\
\left.\text { (HAB./KM }{ }^{2}\right)\end{array}$ & $\begin{array}{l}\text { VARIAÇÃO } \\
(2000-10 ; \%)\end{array}$ & $\begin{array}{c}\text { MULHERES } \\
(\%)\end{array}$ & $\begin{array}{c}\text { POPULAÇÃO } \\
\text { RURAL (\%) }\end{array}$ & $\begin{array}{c}\text { DESEMPREGO } \\
(\%)\end{array}$ \\
\hline Cabo Verde & 491683 & 122 & 13,1 & 50,5 & 38,2 & 10,7 \\
\hline Ilha de Santiago & 273919 & 276 & 15,8 & 52,0 & 39,2 & 11,8 \\
\hline Praia & 131602 & 1295 & 34,1 & 50,9 & 2,9 & 11,3 \\
\hline Tarrafal & 18565 & 154 & 4,3 & 54,8 & 66,7 & 10,1 \\
\hline S. Miguel & 15648 & 202 & $-3,0$ & 55,1 & 73,0 & 10,6 \\
\hline
\end{tabular}

Fonte: INE - Instituto Nacional de Estatística.

Até aos anos 60 do século passado, grande parte dos edifícios da ilha de Santiago era feita de pedras soltas sem argamassa e coberta por materiais de origem vegetal como folhas de carrapato (Furcraea gigantea) ou mesmo de palha de cana-de-açúcar (Saccharum officinalis) (AMARAL, 1964, p. 253-254). Nos finais dos anos 60 e início dos anos 70 do século passado, com o incremento das secas no arquipélago, registou-se alguma limitação da utilização de materiais de origem vegetal local na cobertura das casas. Passaram, a partir de então, a ser utilizadas a madeira e as telhas convencionais, mas estes materiais, escassos nas ilhas, eram de difícil aquisição dados os elevados custos de importação (MAAP e GEP, 2003, p. 23).

Em 1992, com a liberalização da importação de cimento, foi promovida uma nova técnica de construção civil, com aplicação de blocos de cimento nas paredes e betão armado nas coberturas (Idem, ibidem). Este progresso, aliado ao incremento da rede rodoviária, ao crescimento da população e à forte migração do campo para as cidades fez aumentar nestas a construção civil, e por conseguinte, levou a uma crescente procura de inertes (areias e cascalhos) e desenvolveu o mercado da sua comercialização. Com exceção das ilhas rasas, situadas a oriente do país (Sal, Boavista e Maio), as restantes ilhas vulcânicas apresentam vertentes com declives acentuados e uma plataforma continental minúscula ou mesmo inexistente, pelo que falta a areia de boa qualidade para a construção. A escassez deste recurso e a sua valorização comercial levaram à exploração espontânea de inertes, não enquadrada do ponto de vista legislativo (pelo menos até ao início dos anos 90, data da criação do Decreto-Lei da exploração de inertes). Esta exploração, apesar de feita em condições muito difíceis nas praias ou nos vales das ribeiras principais, continua a desenvolver-se hoje de forma crescente e com fortes impactes ambientais (LOPES, 2010, p. 40). 
Por outro lado, a forte emigração que afeta, sobretudo, a população masculina, não deixa de ter um impacto significativo na situação económica e social das mulheres cabo-verdianas (GOMES, 2007, p. 536), particularmente nas áreas rurais. Com a emigração do marido - muitas vezes, para trabalhos precários e com condições económicas difíceis - quem passa a ser responsável pela subsistência da família, mesmo em termos financeiros, é a mulher que exercia até então, sobretudo, tarefas de carácter doméstico (cozinhar, cuidar da casa, tratar dos filhos, etc.) e de subsistência primária (na agricultura e na pecuária). A mulher passa a sentir necessidade de recorrer o mercado formal do trabalho remunerado. No entanto, este acesso é fortemente dificultado pelo baixo nível de escolaridade, pela falta de formação qualificada e pela própria tradição cultural. Assim, para contornar a situação, a mulher recorre, geralmente, a um conjunto de atividades de economia informal, em que se destaca a difícil tarefa da extração clandestina de inertes nos fundos das ribeiras e nas faixas costeiras (LOPES, 2010, p. 16).

Apesar de não se tratar, propriamente, de um estudo de Geografia do Género neste estudo pretendemos apresentar alguns aspetos que marcam claramente a diferenciação imposta pelo género no mercado de trabalho, por via daquilo que são as diferenças de reconhecimento social e de remuneração económica das tarefas desenvolvidas.

Como refere Irene Dankelman (2010), citando S. Ortner (1974), sobretudo nos países menos desenvolvidos, a mulher está quase sempre mais próxima das atividades ligadas à natureza enquanto o homem fica mais perto das atividades ligadas à cultura e à técnica. Por isso, a mulher desempenha, em regra, um importante papel no uso e amanho da terra, na recolha extrativista na floresta, no abastecimento domiciliário de água, etc... Segundo Dankelmen e Jansen (2010), por todo o lado mulheres e homens desempenham diferentes papéis na gestão dos recursos naturais a nível local, cabendo-lhes responsabilidades e direitos distintos, particularmente no que diz respeito ao acesso e controle destes recursos.

Neste contexto, com o presente trabalho pretendemos analisar a importância social das mulheres no processo extrativo clandestino, avaliar os impactes ambientais decorrentes da exploração de inertes, estudar a diferenciação dos impactes em função do local da exploração, no caso, nas Ribeiras de Flamengos e de Principal, no concelho de S. Miguel e na Cuba, no concelho de Tarrafal, e por fim, tentar explicar como é que as mulheres podem participar e contribuir para uma extração mais sustentável e, consequentemente, para a redução do processo extrativo clandestino e dos seus impactes ambientais.

Do ponto de vista metodológico apoiamo-nos na bibliografia existente sobre Cabo Verde e, particularmente, sobre a ilha de Santiago, nos dados estatísticos produzidos pelo INE, na cartografia de base digital e na observação direta e participativa no terreno, a qual possibilitou a construção das matrizes de interação para avaliação de impactes ambientais, o registo das áreas degradadas em fotografias e a realização dos inquéritos às populações que extraem, clandestinamente, os inertes.

\section{ÁREA DE ESTUDO}

A área de estudo compreende os concelhos de S. Miguel e Tarrafal, dois dos nove da ilha de Santiago, de constituição geológica vulcânica. No primeiro, localizado na parte litoral Este, predomina, do ponto de vista geológico, o Complexo Eruptivo do Pico da Antónia (PA), a formação mais desenvolvida e espessa da ilha (PINA et al., 2006), bem como a responsável pelas maiores elevações e plataformas estruturais (VICTÓRIA, 2006, p. 61). A sul do concelho aflora, também, a Formação de Flamengos (mantos, brechas, piroclastos; fig.2). No concelho de Tarrafal, localizado na parte litoral Norte (figura1) predomina, também, o PA e, mais a norte, aparecem as unidades de base: pequenos afloramentos de Formação dos Órgãos e, mais raramente, a Formação Vulcânica de Base (fig.2). Estas formações são caracterizadas por um grau elevado de compacidade quando se trata de rocha sã, por uma significativa alteração e uma baixa permeabilidade, relativamente, 
às formações geológicas sedimentares detríticas mais recentes, a Formação do Monte das Vacas e as escassas manchas de aluviões (PINA et al., 2006). Em ambos os concelhos se encontram nos fundos dos leitos das ribeiras e nas faixas costeiras, em quantidade apreciáveis e passíveis de serem exploradas, os sedimentos aluvionares, resultantes do processo químico-mecânico da alteração das rochas basálticas, do seu transporte e deposição através dos cursos de água torrenciais (figura 1).

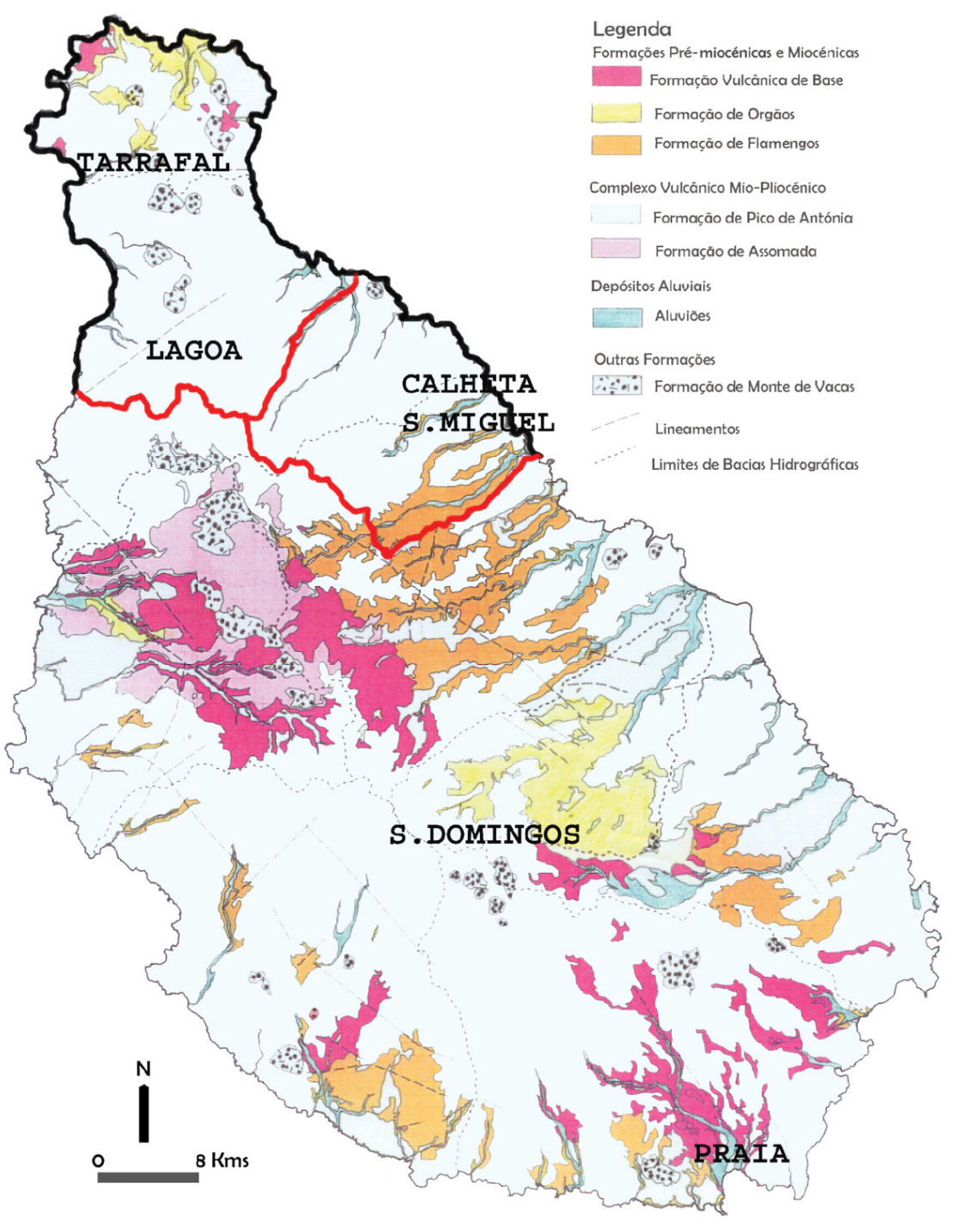

Figura 1 - Mapa geológico da área de estudo Fonte: Adaptado de AJCI e INGRH, 1999:4-11

Em termos demográficos, em 2000 residiam, no concelho de S. Miguel, 16213 habitantes, e, no concelho de Tarrafal, 17883. Em 2010 esses quantitativos eram de 15648 e 18565 habitantes, o que significa uma perda de 3\% e um ganho de $4 \%$, respetivamente (figuras 2 e 3 ). Trata-se, quer num, quer no outro concelho, de populações predominante rurais que, apesar da escassez e da irregularidade da precipitação, continuam a ter como principais atividades económicas as atividades do sector primário, nomeadamente, a agricultura de sequeiro e a pecuária. Esta população rural continua a ser essencialmente feminina $(54,8 \%$, no caso do Tarrafal, e 55,1\%, no caso de S. Miguel, segundo os dados de 2010).

Em ambos os concelhos, o desemprego situa-se ligeiramente abaixo do valor médio nacional que é de $10,7 \%$ (10,1 e 10,6\%, respetivamente nos concelhos de Tarrafal e de S. Miguel) e, como acontece com o resto do país, é maior no sexo feminino do que no sexo masculino, fruto de uma dinâmica económica que tem sido incapaz de absorver grande parte da força de trabalho da popu- 
lação em idade ativa, principalmente, durante os longos períodos de seca, em que as populações mais precárias, nomeadamente, as mulheres chefes de família são conduzidas para trabalhos no sector informal da economia, enquanto os homens procuram saída na emigração.

O rápido crescimento demográfico da ilha, e principalmente do concelho da Praia (131719 habitantes em 2010;29\% de crescimento na última década), vai necessariamente refletir-se na procura de habitação, no dinamismo da construção civil (não só a nível das casas, mas também das infraestruturas viárias, portuárias e aeroportuárias) e, consequentemente, na procura de inertes.

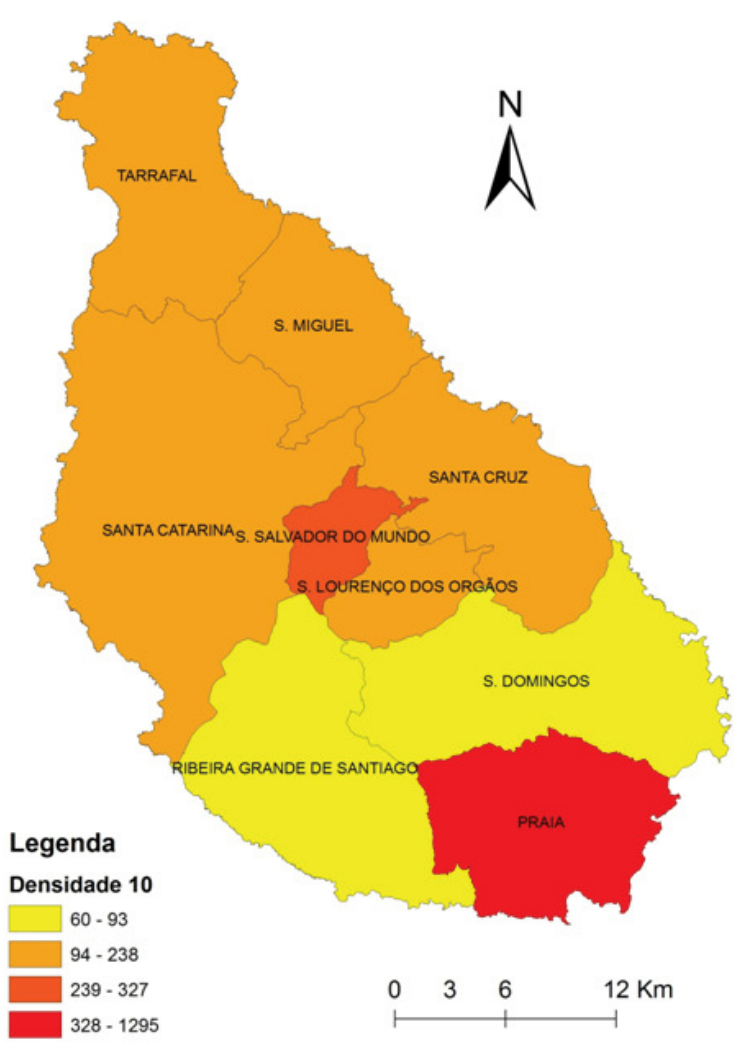

Figura 2 - Densidade demográfica (2010)

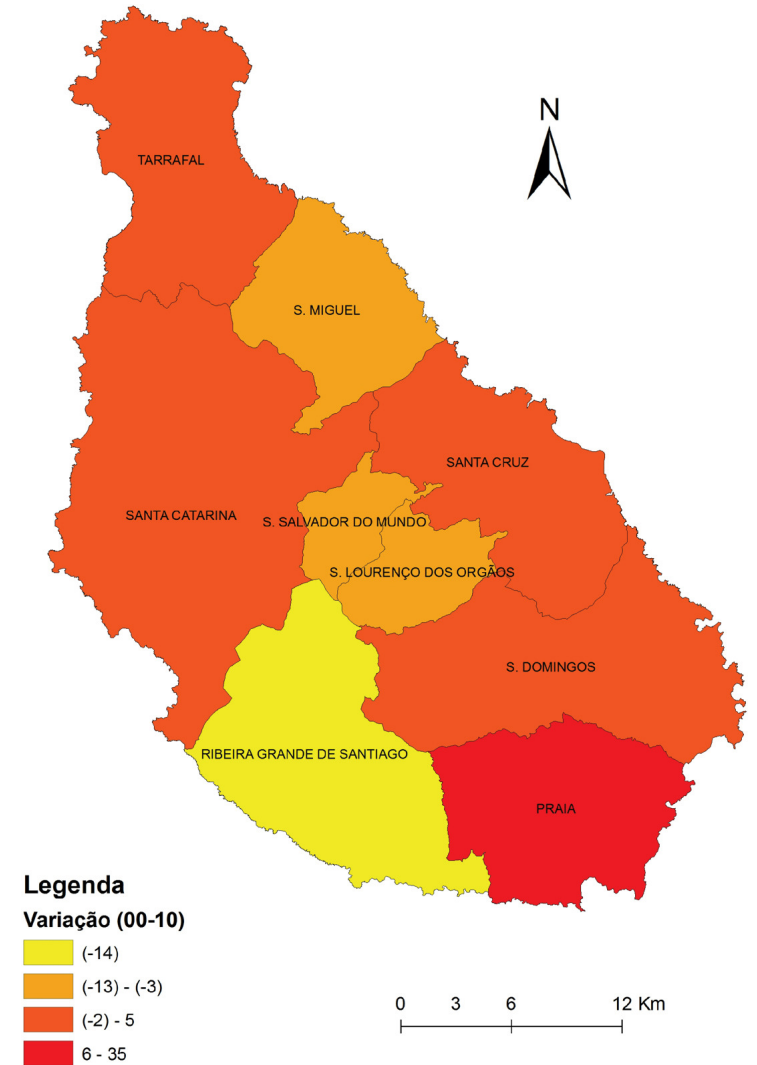

Figura 3 - Variação da população (2000-2010)

(Fonte: INE - Instituto Nacional de Estatística)

\section{APANHA DE INERTES (AREIAS E CASCALHOS) E IMPACTES AMBIENTAIS}

Na ilha de Santiago e, particularmente, nas Ribeiras de Flamengos e de Principal, no concelho de S. Miguel, e em Cuba, no concelho de Tarrafal (figura 4), a extração clandestina de areias e cascalhos para a construção civil tem sido feita de forma muito intensa e sem qualquer plano de extração e de recuperação das áreas degradadas (LOPES, 2010).

Geralmente, a extração, feita quase exclusivamente por mulheres, baseia-se principalmente na força do trabalho braçal, com utilização de materiais muito simples (enxada, picareta, pá, balde, ciranda e bacia) e é feita sem qualquer controle da quantidade de inertes extraídos. Em regra, a unidade de medida é a "carrada", calculada a partir da capacidade aproximada do veículo de transporte, Toyota Dyna 250 ou Camião Volvo. Para se conseguir alguma economia de escala e, consequentemente, maiores rendimentos, o trabalho é feito, geralmente, em grupos de duas ou mais pessoas com afinidades familiares ou de vizinhança entre si (Idem: Ibidem).

Com vista ao estudo das condições de trabalho foram elaborados e lançados no terreno inquéritos, que foram preenchidos em grupo, pelo que representam apenas a caracterização pessoal do leader de cada grupo. 


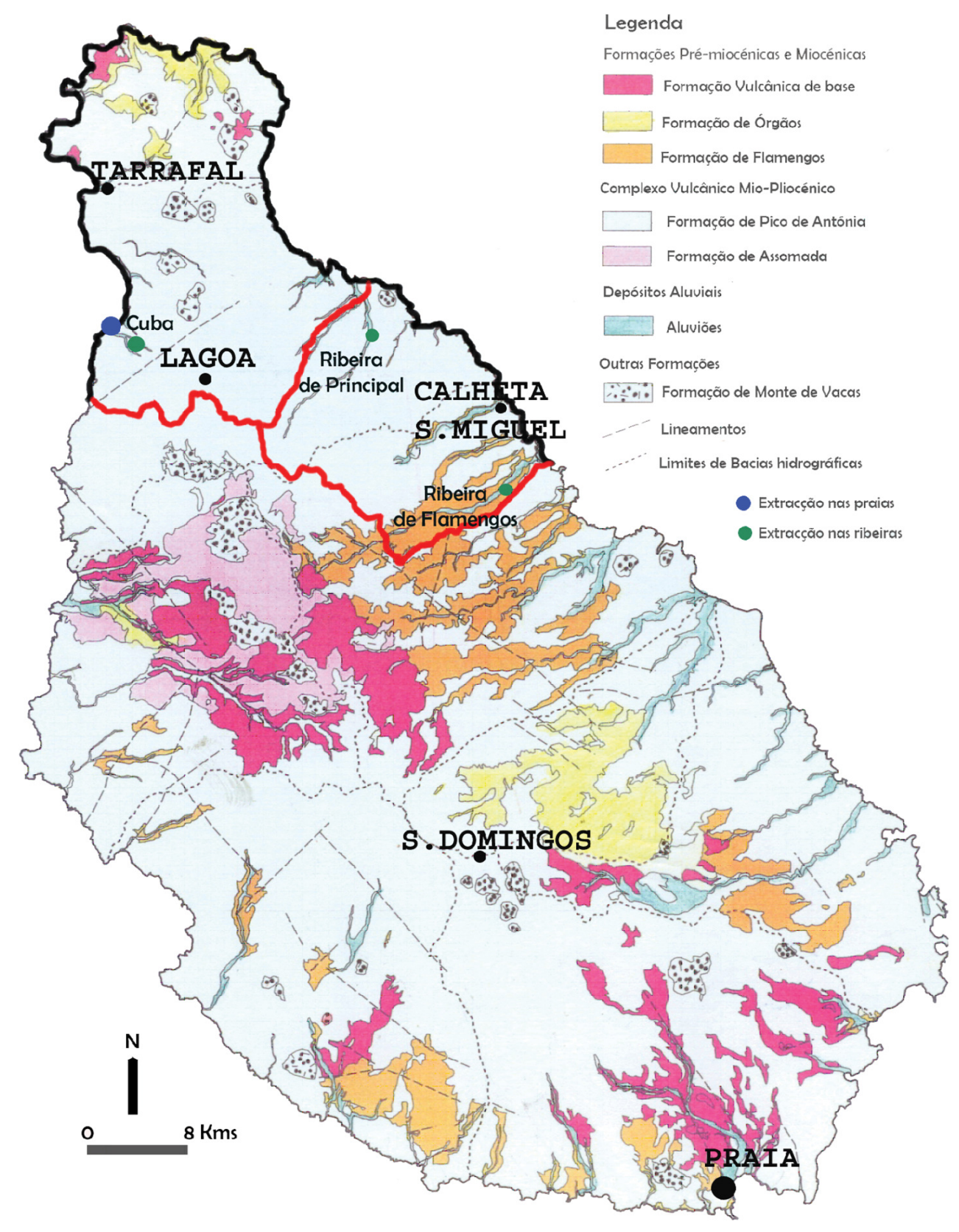

Figura 4 - Localização dos locais de extração Fonte: Adaptado de AJCI e INGRH, 1999:4-11

No total foram inquiridos 80 grupos, o que corresponde a 213 indivíduos. Deste universo, 90\% são mulheres (figura 5). Como foi referido, a predominância de mulheres nesta atividade extrativa clandestina deve-se, ao baixo nível de escolaridade, à ausência de formação profissional qualificada, à emigração maciça da população masculina e ainda, a outros fatores sociais e culturais, em que se destacam a gravidez precoce e a consequente necessidade de a mulher assumir o seu papel de chefe de família.

Para além das mulheres chefes de família, afetadas pelo desemprego e situação económica e social precária, deparámos também com crianças, idosos e alguns homens adultos. Nestes casos, a atividade é exercida, quase sempre, a tempo parcial. No caso das crianças, por causa da escola. Grande parte das crianças encontradas afirma frequentar a escola e exercer a atividade extrativa apenas no âmbito da entreajuda familiar, justificada pelas mães pela falta de ocupação dos tempos livres e, sobretudo, pela ausência do progenitor. A presença muito parcial dos idosos na atividade 
extrativa encontra justificação nas condições de saúde e na própria idade, incompatíveis com o esforço físico necessário. A presença dos homens adultos é ditada por questões pessoais, em regra conjunturais, de grande necessidade económica. Dito por outras palavras, no caso dos jovens, à medida que aumenta a idade e a maturidade física e psicológica, aumenta também, o receio e mesmo a vergonha dos homens exercerem esta atividade, até pela forte exploração económica a que são sujeitos, uma vez que se trata de uma tarefa difícil, perigosa e de muito baixo rendimento. $\mathrm{O}$ rendimento mensal de uma pessoa envolvida na atividade extrativa será de pouco mais de 3600 escudos ( $35 €$; quadro 2). Se for feita nas ribeiras, a extração exige, para além do esforço físico, uma elevada carga horária ( 8 horas diárias), e se for feita na faixa costeira, para além do esforço físico, são necessários o conhecimento das correntes marinhas e, mesmo, a prática ocasional de natação, o que nem sempre se verifica. Os chamados "camionistas" acabam por ser os grandes beneficiados deste processo extrativo.

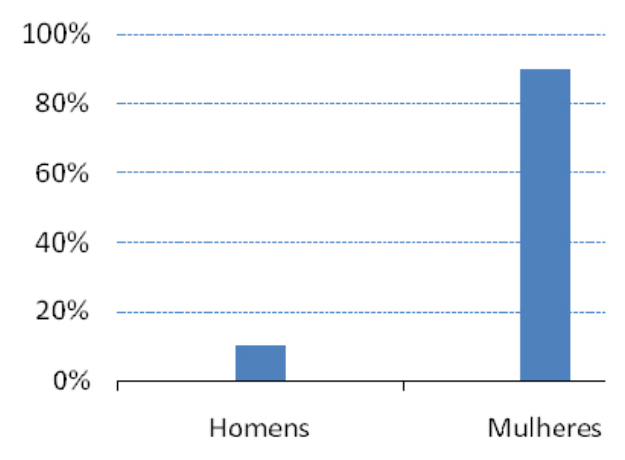

Figura 5 - População inquirida por sexo

Quadro 2: Rendimento médio (em escudos cabo-verdianos) por inquirido e grupos nos diferentes locais de extração

\begin{tabular}{|c|c|c|}
\hline LOCAIS DE EXTRACÇÃO & VALOR MÉDIO POR PESSOA & VALOR MÉDIO POR GRUPO \\
\hline Praia (Cuba) & 1500 & 7500 \\
\hline $\begin{array}{c}\text { Ribeira (Ribeiras de Flamengos, Principal e } \\
\text { Cuba) }\end{array}$ & 3382 & 8808 \\
\hline Praia/Ribeira & 4460 & 10947 \\
\hline Valor médio & $\mathbf{3 6 1 5}$ & 9625 \\
\hline
\end{tabular}

Portanto, nos dois concelhos, cada vez mais os fundos das ribeiras e a faixa costeira vêm afirmando a sua importância na economia das populações, principalmente, das mulheres chefes de família (figura 6), ainda que já não se possa contemporizar durante muito mais tempo com os impactes ambientais decorrentes desta atividade (GOMES, 2011).

Para proceder a uma avaliação simples destes impactes construímos as matrizes de interação de Leopold (CUNHA et al., 1999), matrizes de sentido e magnitude (Quadro 3), de incidência espacial (Quadro 4) e de alcance temporal (Quadro 5), que possibilitarão avaliar de forma rápida e direta a relação impactante das diferentes fases da exploração clandestina de inertes nos elementos ambientais. 


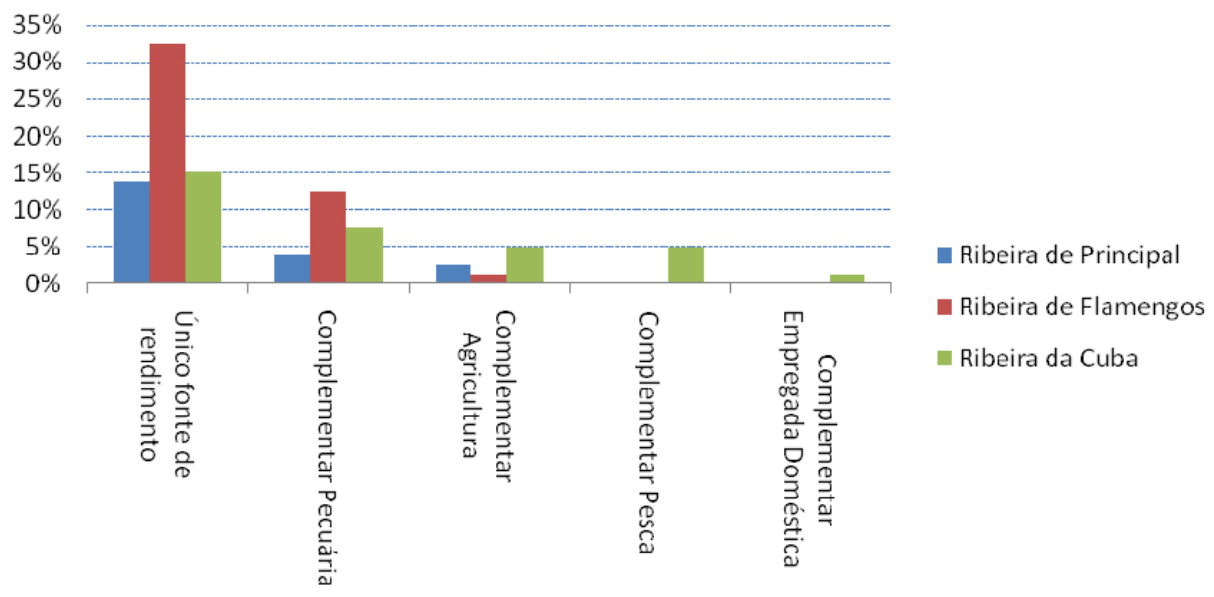

Figura 6 - Importância da atividade extrativa no quotidiano dos inquiridos

Em cada matriz foram consideradas seis classes de valorização dos impactes, três positivas e três negativas (Quadros 3A, 4A, e 5A), cujo somatório permitirá hierarquizar quer as fases de exploração, enquanto geradoras de impactes ambientais, quer os elementos do ambiente mais afetados.

Assim, ao analisarmos a matriz de sentido e magnitude (Quadro 3) tiramos as seguintes conclusões:

- A exploração clandestina de inertes provoca, essencialmente, impactes negativos de maiores magnitudes;

- A extração na faixa costeira (Cuba) gera impactes mais significativos na erosão costeira do que, verdadeiramente, na morfologia costeira, uma vez que a extração provoca de imediato a destruição das praias com potencialidades para o desenvolvimento da atividade turística e funções balneares, bem como a destruição de nichos ecológicos de algumas espécies marinhas, como por exemplo, a tartaruga. Dado que grande parte da costa cabo-verdiana, particularmente na ilha de Santiago, é alta e rochosa, os efeitos erosivos demorarão muito tempo a manifestar-se em termos de modificação morfológica efetiva;

- Na Cuba, a extração na faixa costeira provoca impactes negativos ainda que pouco significativos nas águas subterrâneas, porque não encontramos furos ou poços próximos da faixa costeira;

- A atividade extrativa nas ribeiras altera significativamente a morfologia dos solos, podendo induzir a sua instabilidade e, nalguns casos, mesmo, o desabamento de blocos e terras. Por exemplo, se na cava não foram tomadas as devidas precauções que o processo extrativo exige, a falta de base de apoio pode originar desabamentos, ou então, as fissuras criadas geram situações de queda de blocos de diversas dimensões, que constituem um risco significativo para as populações que ali extraem os inertes;

- A atividade extrativa nas ribeiras provoca alterações na rede de drenagem natural das águas das cheias, que favorecida pela presença dos materiais rochosos e incoerentes e pela falta de vegetação desencadeiam uma intensa erosão hídrica; 
Quadro 3 - Matriz de sentido e magnitude dos impactes ambientais decorrentes da exploração clandestina de inertes

\begin{tabular}{|c|c|c|c|c|c|c|}
\hline \multicolumn{2}{|c|}{ Ambiente } & \multirow[b]{2}{*}{ Impactes } & \multicolumn{2}{|c|}{ Atividades extrativas } & \multirow[b]{2}{*}{$\begin{array}{l}\text { Armaze- } \\
\text {-namento }\end{array}$} & \multirow[b]{2}{*}{$\begin{array}{l}\text { Transporte } \\
\text { de Inertes }\end{array}$} \\
\hline Elementos & Sub-elementos & & $\begin{array}{c}\text { Nas ribeiras } \\
\text { (Flamengos, } \\
\text { Principal e } \\
\text { Cuba) }\end{array}$ & $\begin{array}{c}\text { Na faixa } \\
\text { costeira } \\
\text { (Cuba) }\end{array}$ & & \\
\hline \multirow{12}{*}{ Terra } & \multirow{2}{*}{ Litoral } & Morfologia da costa & & -1 & & \\
\hline & & Erosão costeira & -1 & -3 & & \\
\hline & & $\begin{array}{l}\text { Rompimento das barreiras entre o mar e a } \\
\text { terra }\end{array}$ & & -1 & & \\
\hline & \multirow{3}{*}{ Continente } & Inundações & & -1 & & \\
\hline & & Alteração da geometria dos leitos & -3 & & -1 & \\
\hline & & Desabamentos e Deslizamentos & -2 & & & \\
\hline & \multirow{4}{*}{ Solos } & Destruição do solo arável & -3 & & -1 & \\
\hline & & Contaminação & -1 & & & -1 \\
\hline & & Salinização & & -3 & & \\
\hline & & Compactação & & & -1 & -1 \\
\hline & \multirow{2}{*}{$\begin{array}{l}\text { Rochas e Mi- } \\
\text { nerais }\end{array}$} & Redução das reservas dos inertes & -3 & -3 & & \\
\hline & & Aumento de materiais rochosos incoerentes & -3 & -3 & & \\
\hline Ar & Qualidade do ar & Emissão de poeiras e fumos & -1 & & -1 & -2 \\
\hline \multirow{4}{*}{ Água } & $\begin{array}{l}\text { Águas } \\
\text { superficiais }\end{array}$ & $\begin{array}{l}\text { Concentração de partículas sólidas em sus- } \\
\text { pensão }\end{array}$ & -3 & -2 & & \\
\hline & \multirow{3}{*}{$\begin{array}{l}\text { Águas } \\
\text { subterrâneas }\end{array}$} & Qualidade & -1 & -1 & & \\
\hline & & Salinização & & -1 & & \\
\hline & & Nível freático & -1 & -1 & & -1 \\
\hline \multirow{4}{*}{ Vida } & Flora & Destruição do coberto vegetal & -3 & & -2 & \\
\hline & \multirow{3}{*}{ Fauna } & Destruição dos nichos & -3 & -3 & -1 & -1 \\
\hline & & Migrações & -3 & -3 & & \\
\hline & & Perda do habitat & -3 & -3 & & \\
\hline \multicolumn{2}{|c|}{ Paisagem } & Alteração da qualidade & -3 & -3 & -2 & \\
\hline \multirow{6}{*}{ Ser Humano } & \multirow{6}{*}{$\begin{array}{l}\text { Aspetos econó- } \\
\text { mico-sociais }\end{array}$} & Material para a construção & 3 & 3 & 3 & 3 \\
\hline & & Emprego & 3 & 3 & 3 & 2 \\
\hline & & Aumento de nível de vida & 1 & 1 & & 2 \\
\hline & & Reforço das redes sociais & 3 & 3 & 3 & -1 \\
\hline & & Risco de saúde & -3 & -3 & -2 & -1 \\
\hline & & Funções balneares/Lazer/Turismo & -1 & -2 & -1 & \\
\hline
\end{tabular}

Quadro 3B - Tabela qualitativa de valoração de impactes

\begin{tabular}{|c|c|c|}
\hline Impactes & Positivos & Negativos \\
\hline Pouco significativo & 1 & -1 \\
\cline { 2 - 3 } Moderado & 2 & -2 \\
Significativo & 3 & -3 \\
\hline
\end{tabular}

Fonte: Trabalho de campo, com adaptação de Cunha et al., 1999 
LOPES, E.; CUNHA, L.

Quadro 4 - Matriz de incidência espacial dos impactes ambientais decorrentes da exploração clandestina de inertes

\begin{tabular}{|c|c|c|c|c|c|c|}
\hline \multicolumn{2}{|c|}{ AMBIENTE } & \multirow{2}{*}{ IMPACTES } & \multicolumn{2}{|c|}{$\begin{array}{c}\text { ATIVIDADES EXTRA- } \\
\text { TIVAS }\end{array}$} & \multirow{2}{*}{$\begin{array}{l}\text { Armaze- } \\
\text {-namento }\end{array}$} & \multirow{2}{*}{$\begin{array}{l}\text { Transporte } \\
\text { de Inertes }\end{array}$} \\
\hline Elementos & Sub-elementos & & $\begin{array}{c}\text { Nas ribeiras } \\
\text { (Flamengos, } \\
\text { Principal e } \\
\text { Cuba) }\end{array}$ & $\begin{array}{l}\text { Na faixa } \\
\text { costeira } \\
\text { (Cuba) }\end{array}$ & & \\
\hline \multirow{12}{*}{ Terra } & \multirow{2}{*}{ Litoral } & Morfologia da costa & & -1 & & \\
\hline & & Erosão costeira & -1 & -1 & & \\
\hline & & $\begin{array}{l}\text { Rompimento das barreiras entre o mar e } \\
\text { a terra }\end{array}$ & & -1 & & \\
\hline & \multirow{3}{*}{ Continente } & Inundações & -1 & -1 & & \\
\hline & & Alteração da geometria dos leitos & -1 & & -1 & \\
\hline & & Desabamentos e Deslizamentos & -1 & & & \\
\hline & \multirow{4}{*}{ Solos } & Destruição do solo arável & -1 & & -1 & \\
\hline & & Contaminação & & & & -1 \\
\hline & & Salinização & & -1 & & \\
\hline & & Compactação & & & -1 & -1 \\
\hline & \multirow{2}{*}{$\begin{array}{l}\text { Rochas e Mine- } \\
\text { rais }\end{array}$} & Redução das reservas dos inertes & -2 & -2 & & \\
\hline & & Aumento de materiais rochosos incoerentes & -1 & -1 & & \\
\hline Ar & Qualidade do ar & Emissão de poeiras e fumos & -1 & & -1 & -1 \\
\hline \multirow{4}{*}{ Água } & $\begin{array}{l}\text { Águas } \\
\text { superficiais }\end{array}$ & $\begin{array}{l}\text { Concentração de partículas sólidas em } \\
\text { suspensão }\end{array}$ & -2 & -1 & & \\
\hline & \multirow{3}{*}{$\begin{array}{l}\text { Águas } \\
\text { subterrâneas }\end{array}$} & Qualidade & -1 & -2 & & \\
\hline & & Salinização & & -2 & & \\
\hline & & Nível freático & -1 & -1 & & -1 \\
\hline \multirow{4}{*}{ Vida } & Flora & Destruição do coberto vegetal & -1 & & -1 & \\
\hline & \multirow{3}{*}{ Fauna } & Destruição dos nichos & -1 & -1 & -1 & -1 \\
\hline & & Migrações & -3 & -3 & & \\
\hline & & Perda do habitat & -1 & -1 & & \\
\hline & Paisagem & Alteração da qualidade & -1 & -1 & -1 & \\
\hline \multirow{6}{*}{ Ser Humano } & \multirow{6}{*}{$\begin{array}{l}\text { Aspetos econó- } \\
\text { mico-sociais }\end{array}$} & Material para a construção & 3 & 3 & 3 & 3 \\
\hline & & Emprego & 2 & 2 & 2 & 3 \\
\hline & & Aumento de nível de vida & 1 & 1 & & 3 \\
\hline & & Reforço das redes sociais & 1 & 1 & 1 & -1 \\
\hline & & Risco de saúde & -1 & -1 & -1 & -3 \\
\hline & & Funções balneares/Lazer/Turismo & -1 & -2 & -1 & \\
\hline
\end{tabular}

Quadro 4A - Tabela qualitativa de valoração de impactes

\begin{tabular}{|l|c|c|}
\hline \multicolumn{1}{|c|}{ Impactes } & Positivos & Negativos \\
\hline Local & 1 & -1 \\
\hline Regional & 2 & -2 \\
\hline Supra-regional & 3 & -3 \\
\hline
\end{tabular}

Fonte: Trabalho de campo, com adaptação de Cunha et al., 1999 
Quadro 5 - Matriz de alcance temporal dos impactes ambientais decorrentes da exploração clandestina de inertes

\begin{tabular}{|c|c|c|c|c|c|c|}
\hline \multicolumn{2}{|c|}{ AMBIENTE } & \multirow{2}{*}{ IMPACTES } & \multicolumn{2}{|c|}{$\begin{array}{l}\text { ATIVIDADES EXTRA- } \\
\text { TIVAS }\end{array}$} & \multirow{2}{*}{$\begin{array}{l}\text { Armaze- } \\
\text {-namento }\end{array}$} & \multirow{2}{*}{$\begin{array}{l}\text { Transporte } \\
\text { de Inertes }\end{array}$} \\
\hline Elementos & Sub-elementos & & $\begin{array}{c}\text { Nas ribeiras } \\
\text { (Flamengos, } \\
\text { Principal e } \\
\text { Cuba) }\end{array}$ & $\begin{array}{l}\text { Na faixa } \\
\text { costeira } \\
\text { (Cuba) }\end{array}$ & & \\
\hline \multirow{12}{*}{ Terra } & \multirow{2}{*}{ Litoral } & Morfologia da costa & & -2 & & \\
\hline & & Erosão costeira & -2 & -2 & & \\
\hline & & $\begin{array}{l}\text { Rompimento das barreiras entre o mar e a } \\
\text { terra }\end{array}$ & & -2 & & \\
\hline & \multirow{3}{*}{ Continente } & Inundações & -1 & -2 & & \\
\hline & & Alteração da geometria dos leitos & -2 & & -2 & \\
\hline & & Desabamentos e Deslizamentos & -1 & & & \\
\hline & \multirow{4}{*}{ Solos } & Destruição do solo arável & -2 & & -1 & \\
\hline & & Contaminação & & & & -2 \\
\hline & & Salinização & & -2 & & \\
\hline & & Compactação & & & -2 & -2 \\
\hline & \multirow{2}{*}{$\begin{array}{l}\text { Rochas e Mine- } \\
\text { rais }\end{array}$} & Redução das reservas dos inertes & -2 & -2 & & \\
\hline & & Aumento de materiais rochosos incoerentes & -2 & -2 & & \\
\hline Ar & Qualidade do ar & Emissão de poeiras e fumos & -1 & & -1 & -1 \\
\hline \multirow{4}{*}{ Água } & $\begin{array}{l}\text { Águas } \\
\text { superficiais }\end{array}$ & $\begin{array}{l}\text { Concentração de partículas sólidas em } \\
\text { suspensão }\end{array}$ & -1 & -1 & & \\
\hline & \multirow{3}{*}{$\begin{array}{l}\text { Águas } \\
\text { subterrâneas }\end{array}$} & Qualidade & -2 & -2 & & \\
\hline & & Salinização & & -2 & & \\
\hline & & Nível freático & -2 & -1 & & -1 \\
\hline \multirow{4}{*}{ Vida } & Flora & Destruição do coberto vegetal & -2 & & -1 & \\
\hline & \multirow{3}{*}{ Fauna } & Destruição dos nichos & -2 & -2 & -1 & \\
\hline & & Migrações & -2 & -2 & & \\
\hline & & Perda do habitat & -2 & -2 & & \\
\hline \multirow{7}{*}{ Ser Humano } & Paisagem & Alteração da qualidade & -2 & -2 & -2 & \\
\hline & \multirow{6}{*}{$\begin{array}{l}\text { Aspetos econó- } \\
\text { mico-sociais }\end{array}$} & Material para a construção & 2 & 2 & 2 & 2 \\
\hline & & Emprego & 1 & 1 & 1 & 1 \\
\hline & & Aumento de nível de vida & 1 & 1 & & 1 \\
\hline & & Reforço das redes sociais & 3 & 3 & 3 & -1 \\
\hline & & Risco de saúde & -3 & -3 & -3 & -2 \\
\hline & & Funções balneares/Lazer/Turismo & -2 & -2 & -2 & \\
\hline
\end{tabular}

Quadro 5A - Tabela qualitativa de valoração de impactes

\begin{tabular}{|l|c|c|}
\hline \multicolumn{1}{|c|}{ Impactes } & Positivos & Negativos \\
\hline Temporário & 1 & -1 \\
\cline { 2 - 3 } Longo prazo & 2 & -2 \\
Permanente & 3 & -3 \\
\hline
\end{tabular}

Fonte: Trabalho de campo, com adaptação de Cunha et al., 1999 


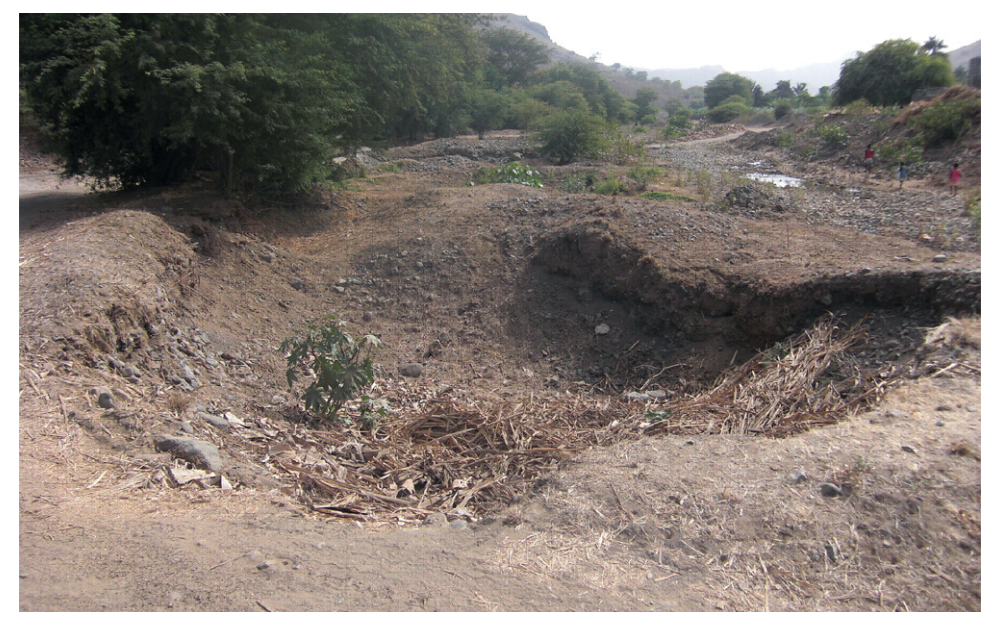

Figura 7 - Impacte na ribeira

- No que diz respeito a aspetos económico-sociais, a exploração de inertes provoca impactes positivos, como a criação de emprego para a população desempregada, a oferta de matérias-primas para a construção civil e o reforço das redes sociais, com exceção dos responsáveis pelos transportes, dada a cumplicidade que existe entre as mulheres e a rivalidade que se gera entre as mulheres e os camionistas na hora da venda dos inertes. Gera, também, impactes negativos na saúde, como problemas respiratórios pela quantidade de fumos e poeiras a que os envolvidos na atividade extrativa estão sujeitos, problemas de visão pelo contacto contínuo com as águas salgadas do mar e lesões musculares decorrentes do esforço repetitivo e da postura inadequada durante muitas horas de trabalho;

- Tanto nas Ribeiras de Flamengos e de Principal, como na Ribeira da Cuba, nos fundos dos vales onde se realizam as extrações, a destruição da flora é tão significativa que atualmente apenas se encontra a acácia americana que, pela extensão das raízes, adquire uma maior resistência às condições extremas e à própria degradação antrópica;

- As emissões de poeiras e fumos associados ao processo de peneiramento, armazenamento e movimentação de veículos constituem impactes negativos não significativos na flora devido à reduzida população vegetal que pode ser afetada. No transporte, consideramos ainda, a possibilidade de atropelamento de espécies animais existentes e a degradação dos seus habitats, a possibilidade de ocorrerem acidentes de viação e de ocorrerem derrames de óleos, que poderão poluir o solo descoberto ou os lençóis freáticos;

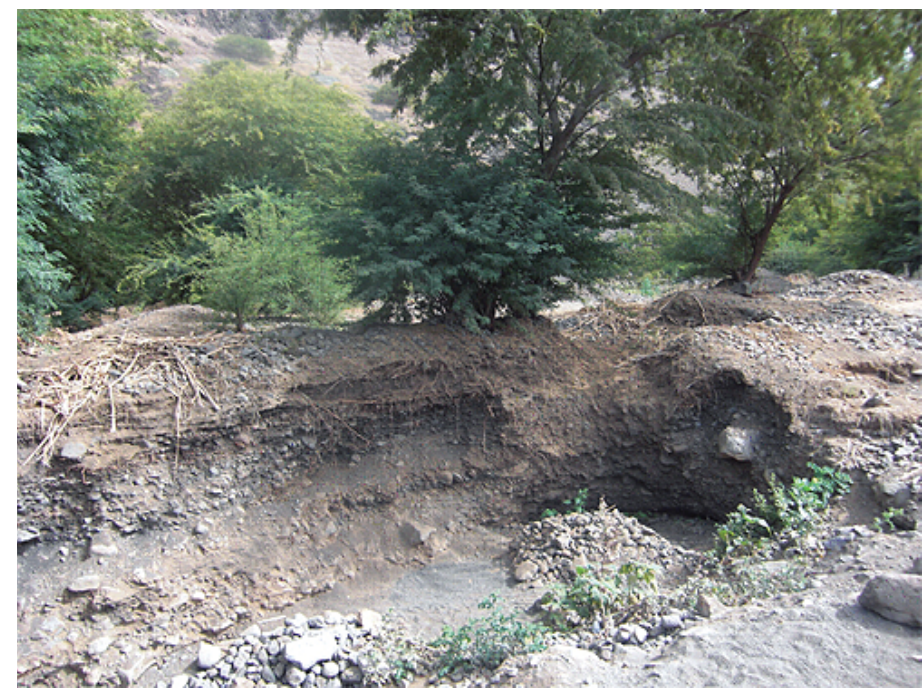

Figura 8 - Impacte na flora 
- As extrações clandestinas de inertes provocam impactes negativos significativos na fauna, pelo facto, de serem feitas em nichos ecológicos de muitas espécies endémicas com real importância na biodiversidade nacional;

- O aumento de nível de vida é um impacte positivo mas pouco significativo, porque os lucros resultantes da atividade extrativa permitem apenas a satisfação das necessidades básicas, nomeadamente, a aquisição de bens alimentícios.

Da análise da matriz de incidência espacial (Quadro 4) destacam-se as seguintes conclusões:

- A exploração clandestina de inertes provoca, essencialmente, impactes negativos de incidência local, o que significa que, "os impactes são tanto mais intensos quanto mais próximos das áreas de explorações se situam os elementos e os sub-elementos da Natureza" (MAAP e GEP, 2003:41);

- As ofertas de inertes têm repercussões positivas para a sociedade em geral (local, regional e supra-regional);

- A geração de emprego tem impacte positivo moderado supra-regional para os camionistas e positivo significativo regional para os envolvidos na extração, porque, na análise dos inquéritos não deparámos, em nenhum dos três casos estudados, com pessoas envolvidas na atividade extrativa de outros concelhos;

- A redução das reservas dos inertes constitui um impacte negativo significativo e de caráter regional, porque diminui as areias das praias, o que embora possa ser considerado um impacte local, acaba por ter uma forte implicação no desenvolvimento turístico dos concelhos;

- Os riscos de saúde são impactes negativos locais para as populações envolvidas na extração e supra-regional para os camionistas. Este é justificado pelos possíveis acidentes de viação que podem ocorrer fora do local da extração.

Por último, a matriz de alcance temporal (Quadro 5) permitiu-nos tirar as seguintes conclusões:

- Grande parte dos impactes causados pela exploração clandestina de inertes terá implicações de longo prazo, ou seja, se não foram tomadas medidas de recuperação das áreas degradadas, grande parte dos efeitos negativos apenas se resolve a longo prazo, por si só, no longo e lento processo natural da evolução das ribeiras e das praias;

- A extração clandestina de inertes gera impactes negativos permanentes na saúde dos envolvidos da atividade extrativa e no reforço das redes sociais porque se criam laços de amizade que, mesmo após a extração, têm uma baixa probabilidade de desaparecer;

- O processo de armazenamento por ser muito superficial causa impacte negativo temporário na destruição do solo arável e do coberto vegetal.

Feitas as análises das matrizes individualmente achamos pertinente cruzar as três matrizes de impactes ambientais (Quadros 3, 4 e 5) que permitiram analisar e hierarquizar os impactes no conjunto das fases de exploração (Figura 9) e os impactes para cada fator ambiental considerado (Figura 10). 


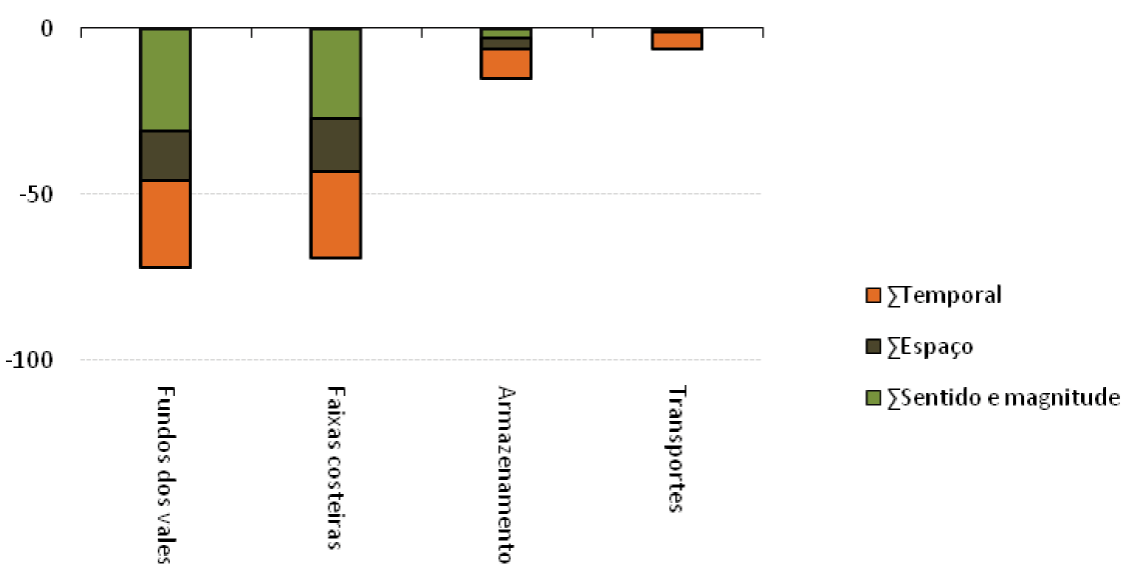

Figura 9 - Impactes no conjunto da exploração

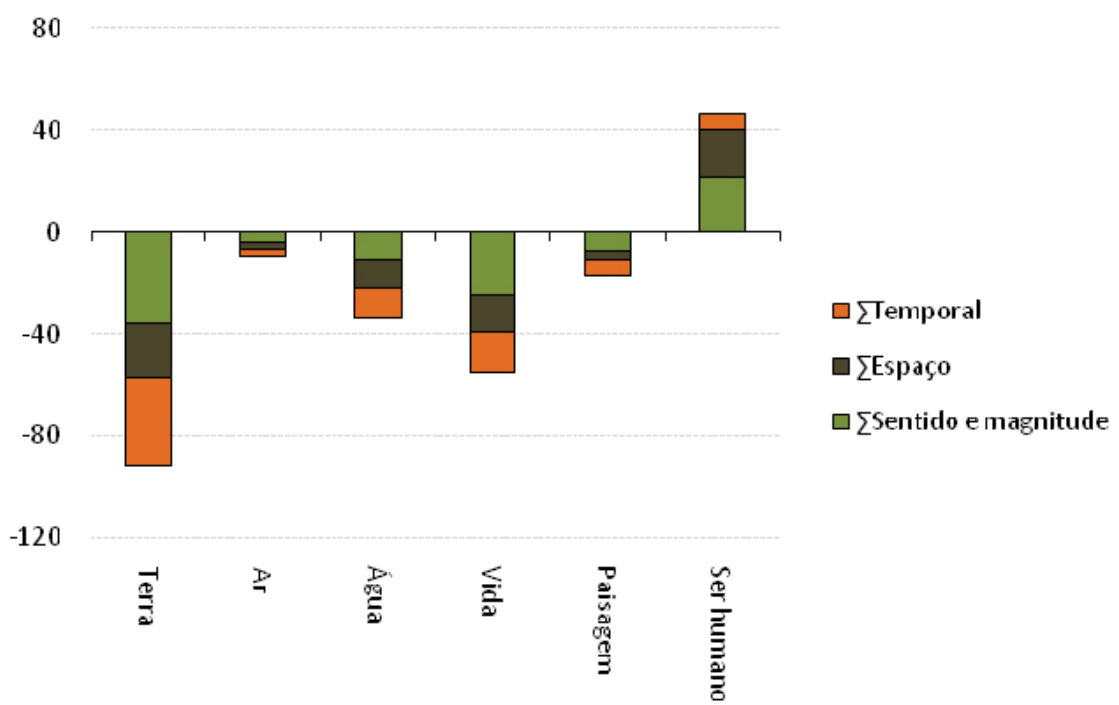

Figura 10 - Impactes para cada elemento do ambiente considerado

Na figura 9 observa-se o predomínio dos impactes negativos, tendo no conjunto, a extração nas ribeiras uma representação de -72 pontos $(44,4 \%)$, na faixa costeira uma representação de -69 pontos $(42,6 \%)$, o armazenamento uma representação de -15 pontos $(9,3 \%)$ e o transporte uma representação de apenas -6 pontos (3,7\%). Entretanto, a figura 10 leva-nos às seguintes conclusões:

- Apenas o elemento Ser Humano sofre impactes positivos, o que resulta essencialmente dos impactes de sentido e magnitude, no caso, a oferta de recursos minerais para a construção civil e a geração de empregos;

. O ar, pela emissão de poeiras e fumos, é o elemento menos penalizado no conjunto da exploração;

A terra é o elemento mais penalizado, particularmente, na redução das reservas de inertes, alteração da geometria dos leitos, destruição do solo arável, erosão das praias e aumento dos materiais rochosos e incoerentes. 


\section{CONSIDERAÇÕES FINAIS}

Atualmente, nos concelhos de S. Miguel e Tarrafal, a necessidade de sobrevivência diária sobrepõe-se à política ambiental. Mesmo com a criação do Decreto-Lei que proíbe a extração clandestina de inertes e com a criação de programas de informação acerca dos seus impactes negativos, muitas pessoas continuam a extrair inertes e recusam-se abandonar esta atividade enquanto não foram criadas novas alternativas de emprego.

E no que diz respeito as populações, principalmente, às mulheres que vivem da extração clandestina de inertes? Neste âmbito, ainda, há muito que fazer. Os envolvidos na atividade extrativa pretendem, em regra, um emprego com rendimento monetário direto sem que tenham de ser elas próprias a financiar a criação do seu próprio emprego.

Assim, e cientes da utilidade da atividade extrativa no país, neste estudo propomos o envolvimento das mulheres, principalmente das que atualmente se encontram envolvidas no processo extrativo clandestino, num processo extrativo feito de modo ambientalmente sustentável. Este poderá conseguir-se com estudos pormenorizados da geologia e geomorfologia das ilhas, a fim de se conhecerem e delimitarem as áreas com potencialidades para a implantação de unidades extrativas industriais, bem como as áreas críticas, onde deve ser absolutamente interdita a exploração. As mulheres hoje envolvidas no processo para além de poderem continuar a trabalhar em unidades industriais a implementar, poderão participar nos planos e nos programas dos transportes de inertes, bem como nos programas de recuperação das áreas já degradadas pela extração clandestina (alimentação das praias, preenchimento das cavas abandonadas, reflorestamento das espécies vegetais, etc.). Finalmente, as mulheres poderão realizar, também, atividades de comunicação, informação e sensibilização de proteção ambiental junto das populações locais.

A atual situação apenas será revertida com a criação de postos de trabalho com remuneração pelo menos igual ou superior à conseguida na atividade extrativa e com mais e melhor educação e formação profissional, principalmente, para as mulheres mais jovens.

$\mathrm{Na}$ escolha das alternativas propostas, acreditamos que no futuro grandes mudanças poderão ser observadas na situação socioeconómica das mulheres que vivem da extração clandestina de inertes, bem como na redução dos impactes de exploração..

\section{REFERÊNCIA BIBLIOGRÁFICA}

AJCI (Agência Japonesa de Cooperação Internacional) e INGRH (Instituto Nacional de Gestão de Recursos Hídricos). Estudo sobre o Desenvolvimento da Água Subterrânea na Ilha de Santiago em República de Cabo Verde. Relatório Final, vol.2. Cabo Verde, 1999.

AMARAL, Ilídio. Santiago de Cabo Verde. A Terra e os Homens. Lisboa, 1964.

CUNHA, Lúcio; SOARES, A. F.; TAVARES, Alexandre; ALMEIDA, A. Campar de e SANTOS, José Gomes. Intervenções Recentes e Avaliação de Impactes Ambientais no Baixo Mondego. Cadernos de Geografia, $\mathrm{n}^{\circ} 18$, Coimbra, pp. 39-52, 1999.

DANKELMAN, Irene e JANSEN, Willy. Gender, Environment and Climate Change: Understanding the Linkages. In: DANKELMAN, Irene. Gender and Climate Change: an Introduction. Londres: 2010, pp. 21-54.

DANKELMAN, Irene. Introduction: Exploring Gender, Environment and Climate Change. In: DANKELMAN, Irene. Gender and Climate Change: an Introduction. Londres: 2010, pp. 1-18.

GOMES, Samuel Fernandes. Avaliação de Impacte de Apanha e Extração de Inertes na Ribeira da Barca - Ilha de Santiago - Cabo Verde. Dissertação para obtenção do Grau de Mestre em Arquitectura Paisagista, Instituto Superior de Agranomia. Lisboa: 2011.

GOMES, Simone. O Texto Literário de Autoria Feminina. Escreve e Inscreve a Mulher e (em) Cabo Verde. In: MATA, Inocência e PADILHA, Laura (org.). A Mulher em África: Vozes de uma Margem Sempre Presente. Lisboa: 2007, pp. 535-558. 
LOPES, Ermelinda. Mulheres e Ambiente. A Problemática da Apanha de Inertes na Ilha de Santiago (Cabo Verde). Dissertação de Mestrado em Geografia Física, Ambiente e Ordenamento de Território, Faculdade de Letras da Universidade de Coimbra. Coimbra: 2010.

MOREIRA, Claudete. A Geografia e o Género: Um Encontro Urbano. Os Tempos e os Espaços nos Territórios de Coimbra. Porto: 2010.

PINA, António; GOMES, Mota; SANTOS, Fernando e ALMEIDA, Eugénio. Caracterização Geoeléctrica da Zona Este (Santa Cruz) da Ilha de Santiago (Cabo Verde). Praia: 2006.

SEMEDO, José e GOMES, Samuel. Impactes de Apanha e Extração de Inertes em Cabo Verde. MAAP (Ministério do Ambiente, Agricultura e Pesca) e GEP (Gabinete de Estudos e Planeamentos), Praia: 2003.

VICTÓRIA, Sónia. Condicionantes Geológicos ao Ordenamento do Território: Uma Aplicação na Região da Praia (Santiago - Cabo Verde). Dissertação de Mestrado em Geociências, Faculdade de Ciências e Tecnologia da Universidade de Coimbra. Coimbra: 2006.

Trabalho enviado em maio de 2012 Trabalho aceito em junho de 2012 